\title{
EAl Endorsed Transactions

\section{An Evaluation method for teaching effect of information technology integrated engineering management course based on data clustering}

\author{
Xiaolin Liu ${ }^{1}$, Congjin Xie ${ }^{1}$, Dawid Połap ${ }^{2, *}$ \\ ${ }^{1}$ School of international business and management, Chongqing Institute of Foreign Studies, Chongqing, China 401120 \\ ${ }^{2}$ Faculty of Applied Mathematics/ RMS, Silesian University of Technology, Poland 44-100 Gliwice
}

\begin{abstract}
Aiming at the problems of poor evaluation effect in the teaching effect evaluation of engineering management specialty, this paper designs a new evaluation method of teaching effect of information technology Fusion Engineering Management Specialty Based on data clustering. The evaluation index system of teaching effect of information technology integration engineering management specialty is established by analytic hierarchy process. The indexes in the system mainly include five secondary indexes: teaching ability, teaching method, teaching content, teaching attitude and teaching effect; Determine the relative importance of different factors and calculate the weight vector of each index; On this basis, according to the established evaluation index system, pso-k-means algorithm is selected to evaluate the course teaching effect. PSO-k-means algorithm runs K-means clustering algorithm in each particle swarm optimization iteration, and uses the clustering result of K-means clustering algorithm as the particle fitness of the evaluation process to obtain accurate course teaching effect evaluation results. The experimental results show that the proposed method can effectively evaluate the teaching effect of information technology integration engineering management course and improve the evaluation effect.
\end{abstract}

Keywords: Data clustering; Information technology; Integration; Engineering management; Course teaching; Effect evaluation

Received on 16 December 2021, accepted on 17 January 2022, published on 26 January 2022

Copyright (C) 2022 Xiaolin Liu et al., licensed to EAI. This is an open access article distributed under the terms of the Creative Commons Attribution license, which permits unlimited use, distribution and reproduction in any medium so long as the original work is properly cited.

doi: 10.4108/eai.26-1-2022.173160

* Corresponding author: Dawid.Polap@polsl.pl

\section{Introduction}

Information technology is the product of the combination of communication technology and computer technology, which shows strong advantages in the process of practical application. With the deepening of people's understanding of information technology, countries all over the world are strengthening national information technology construction [1]. As the most influential factor in the $21 \mathrm{st}$ century, information technology is of great significance to the development of social and economic life. Especially with the continuous improvement of computer technology and network technology, information technology not only promotes the progress in the field of science and technology, but also changes the management in the field of engineering. With the rapid development of information technology, engineering enterprises must introduce information technology into engineering management if they want to maintain the sustainable and good development of enterprises. The integration of information technology and project management can shorten the time required for the project as much as possible [2], and can improve the operation efficiency of the whole construction project business process to a great extent. How to realize the automation of internal management business of engineering enterprises by information technology and engineering management has also changed the manual management mode of construction equipment in the past [3]. Such an intelligent and automatic engineering management mode can not only improve the work efficiency of management activities, but also make construction equipment more efficient because of strict operation standards. Project management is a relatively complex process. Management 
involves all links of construction. In addition, the unique fluidity of project construction makes project management difficult in practical operation. The importance of project management course is self-evident. With the rapid development of China's social economy, the project scale and quantity are gradually increasing, and the complexity of the project is increasing. Under this background, the project management must rely on modern information technology means to realize the professional management of the project [4]. Only by integrating information technology and project management can we reasonably coordinate all links of the project and meet the changing requirements of society and market.

The evaluation of course teaching effect is the basic link of school teaching management, and the evaluation of course teaching effect in colleges and universities can not be ignored. Carrying out course teaching effect evaluation is not only an effective method to measure the classroom teaching quality of college teachers, ensure and improve teachers' teaching level, but also an effective means for the teaching competent department to monitor teachers' Teaching [5], and an important way to help teachers find teaching problems, promote the continuous improvement of college teachers' professional level and improve teaching work. Using association rule mining to analyze the academic achievements of informatics curriculum improvement "and" artificial intelligence, intelligent classroom and online education in the 21 st century: the impact on human development.

At present, the evaluation of classroom teaching quality in most colleges and universities adopts the index system method, which contains multiple single indexes. The scores and weights of individual indicators are greatly affected by human factors, and the correlation between indicators is high, which makes the information cross and redundant, and affects the reliability and rationality of the evaluation results. In the later stage, the simple arithmetic average method and weighted average method are usually used in the process of quantifying the scores of various indicators. This method of taking the mean value to sort the teaching quality of teachers is too simple to obtain more enlightening information on improving the teaching quality [6]. How to select the appropriate weight to obtain a more effective comprehensive evaluation index is a key problem to be solved in teaching quality evaluation. Multivariate statistical methods can effectively solve these problems.

Some researchers have studied the teaching effect. Sunba et al. have studied the impact of teaching methods and course duration on the performance of students with different cognitive levels and different evaluation types [7], and have made a preliminary study on the teaching effect. At present, there are many researches on data clustering. Sheng studied a differential evolution algorithm with adaptive and K-means for data clustering [8]. The differential evolution algorithm combined with adaptive and K-means algorithm is applied to data clustering, which significantly shortens the clustering time; Song et al. applied adaptive regression of fuzzy clustering to drift data streams [9], which also has high clustering effect for drift data streams that are difficult to classify; Fang et al. studied the density peak clustering of complex data with arbitrary shape and density based on adaptive core fusion [10], realized the adaptive clustering of complex data with arbitrary shape and density, and improved the adaptive level of clustering.

Therefore, this paper studies the evaluation method for professional course teaching effect of information technology integrated engineering management based on data clustering. The K-means clustering algorithm is used to cluster the professional course teaching effect of information technology integrated engineering management, and the final evaluation results of course teaching effect are obtained. Experiments show that this method has high effectiveness of course teaching effect evaluation. The main technical route of this paper is as follows:

(1) The evaluation index system of teaching effect of information technology integration engineering management specialty is established by analytic hierarchy process. The indexes in the system mainly include five secondary indexes: teaching ability, teaching method, teaching content, teaching attitude and teaching effect;

(2) Determine the relative importance of different factors and calculate the weight vector of each index;

(3) According to the established evaluation index system, pso-k-means algorithm is selected to evaluate the course teaching effect. Pso-k-means algorithm runs Kmeans clustering algorithm in each particle swarm optimization iteration, and uses the clustering result of $\mathrm{K}$ means clustering algorithm as the particle fitness of the evaluation process to obtain accurate course teaching effect evaluation results.

\section{Design of evaluation method for professional course teaching effect of information technology integrated engineering management}

\subsection{Analysis of teaching indexes of engineering management courses based on K-means clustering algorithm}

$\mathrm{K}$-means clustering algorithm is a classical algorithm based on partition. The core idea of the algorithm is to give a specific data set $D$ and the number $K$ to be clustered ( $K$ is usually given by the user). K-means clustering algorithm divides all the objects used for clustering into $K$ classes according to the law of iterative operation of a distance function. The default cluster center represents a class, and the cluster center refers to the average value of all data in the cluster. Through this algorithm, the evaluation index can be selected as a key point, which can be used as the basis of research. The algorithm has the advantages of fast data processing and 
strong processing indexes. The overall effectiveness of the method can be improved by using the algorithm.

$\mathrm{K}$-means clustering algorithm first needs to input the number of clusters $k$, and then randomly select $k$ samples as the clustering center; By calculating the distance between the remaining samples and the cluster center, the samples are classified into the nearest class [11]; When all samples are calculated, the cluster center is updated according to the current clustering results; Through cyclic iteration, the clustering ends when the objective function meets certain requirements or reaches the maximum number of iterations.

The objective function is used to measure the quality of clustering results, which is defined as follows:

$$
J=\sum_{j=1}^{k} \sum_{i, j \in c_{j}} d\left(x_{i}, c_{j}\right)
$$

Where $x_{i}$ represents the $i$-th sample point, $c_{j}$ represents the cluster center of class $j$, and $d\left(x_{i}, c_{j}\right)$ represents the distance between sample $x_{i}$ and its corresponding cluster center $c_{j}$.

$\mathrm{K}$-means clustering algorithm often uses Euclidean distance to represent the distance between the sample and the cluster center [12]. At this time, the objective function is also called square error criterion function:

$$
J=\sum_{j=1}^{k}\left(\sum_{i, j \in c_{j}}\left\|x_{i}-c_{j}\right\|^{2}\right)
$$

After an iteration, the cluster center needs to be updated. The update formula is:

$$
c_{j}^{*}=\frac{1}{n_{j}} \sum_{i=1}^{n_{j}} x_{i}
$$

In equation (3), $n_{j}$ is the number of samples in class $j$, and $c_{j}^{*}$ is the new cluster center.

The process of K-means clustering algorithm is as follows:

(1) Randomly select $k$ objects are from the samples as the initial clustering centers;

(2) Calculate the distance between the sample and $k$ cluster centers [13], and classify the sample into the nearest class;

(3) Calculate the new cluster center according to equation (3);

(4) Repeat steps (2) and (3) until the end conditions are met;

(5) After the calculation, the clustering results are obtained.

\subsection{Application of cluster analysis in teaching evaluation}

In the course of information technology integrated engineering management, evaluation is a main trend of communication between college teachers and students. This form can enable students to give play to their subjectivity in teaching activities and make a subjective evaluation of teachers' teaching, which plays a positive role in improving teaching quality. Students are irreplaceable in teaching evaluation. Based on students' evaluation of teachers, teachers' teaching effect is evaluated through students' teaching evaluation scores. The teaching evaluation form of the course of information technology integrated engineering management is collected, to sort out the collected data, conduct statistical analysis of relevant data [14], evaluate the teaching situation with a scientific and reasonable evaluation index system, establish a practical course effect evaluation model, and realize the cluster analysis of the course effect evaluation data. Using the typical K-means clustering algorithm, this paper analyzes the relationship between the evaluation indexes in the evaluation model and the students' examination results, finds out the specific factors affecting the teaching activities of the professional course effect evaluation [15], and guides the implementation of teachers' teaching work.

\section{Establishment of hierarchical structure model}

Aiming at the problem of teaching effect evaluation of professional course of information technology integrated engineering management, the general goal of teaching effect evaluation is divided into different secondary goals, such as teaching attitude and teaching ability, and then each secondary goal is decomposed into multiple influencing factors to form a hierarchical structure model.

Analytic hierarchy process decomposes the actual problem into multiple factors, uses the decomposed multiple factors to establish a hierarchical structure, determines the relative importance of different factors, calculates the weight vector of each index, and obtains comprehensive decision-making through judgment.

Analytic hierarchy process can divide the decisionmaking problem into single level or multi-level structure [16]. When dividing the single level structure, $C$ represents the goal, $A_{i}$ represents $n$ evaluation elements subordinate to $C$, and $i$ can range from 1 to $n$. Therefore, the evaluation elements subordinate to $C$ are set according to the actual situation. Decision maker is to evaluate the $n$ elements in the sense of goal, rank them through a series of advantages and disadvantages, and make the weight of relative importance, so as to judge the pairwise comparison of $n$ elements .

The steps of constructing hierarchical structure model by analytic hierarchy process are as follows:

(1) Construct pairwise comparison judgment matrix;

(2) Calculate the relative importance of elements under a single criterion:

Calculate the maximum eigenvalue $\lambda_{\max }$ of matrix

$A$ and its corresponding normalized eigenvector: 


$$
W=\left(w_{1}, w_{2}, \cdots, w_{n}\right)^{T}
$$

Finally, the feature vector $W=\left(w_{1}, w_{2}, \cdots, w_{n}\right)^{T}$ is obtained as the weight vector of the corresponding evaluation unit.

$\lambda_{\max }$ and $W$ are calculated by power method and square root method. matrix

(3) Check the consistency of single level judgment

(a) Calculate consistency index C.I.:

$$
\text { C.I. }=\frac{\lambda_{\max }-n}{n-1}
$$

Where $n$ is the order of the judgment matrix.

(b) Calculate the average random consistency index R.I.

(c) Calculate the consistency ratio $C . R$.

$$
\text { C.R. = C.I. / R.I. }
$$

When $C . R .<0.1$, we can usually accept the consistency of the judgment matrix.

\section{Construction of teaching effect evaluation model based on cluster analysis}

There are many factors that affect the evaluation results of professional courses teaching effect of information technology integrated engineering management. When constructing the evaluation index system of professional courses teaching effect, we need to use a certain method to select the most key factors as the evaluation index . In the evaluation of professional courses teaching effect of information technology integrated engineering management, the distribution of evaluation index weight is very important . Scientific and appropriate distribution makes the final result more in line with the actual teaching situation [17], which can enable us to find the key indicators. Therefore, in the evaluation index system of professional courses teaching effect of information technology integrated engineering management, it is very necessary to use analytic hierarchy process to determine the weight of each index.

Based on the existing teaching evaluation system and the principles to be followed, the evaluation index system of professional courses teaching effect of information technology integrated engineering management is designed, as shown in Table 1.

There are 5 secondary indicators and 24 secondary indicators in the evaluation index system of professional courses teaching effect of information technology integrated engineering management in Table 1, and the value of each secondary indicator is 10 points. Similar evaluation tables are common in colleges and universities in China. Most of the common characteristics of disciplines are extracted from different disciplines as evaluation indicators [18]. In addition to the professional

\begin{tabular}{|c|c|c|}
\hline First level indicator & Secondary indicators & Three-level indicators \\
\hline \multirow{22}{*}{$\begin{array}{l}\text { The Teaching Effect } \\
\text { of Information } \\
\text { Technology } \\
\text { Convergence } \\
\text { Engineering } \\
\text { Management Major } \\
\text { Course }\end{array}$} & & Clear and concise language \\
\hline & & Reasonable teaching schedule \\
\hline & teaching ability & Neat writing on the blackboard \\
\hline & teacriming abminty & Classroom regulation level \\
\hline & & $\begin{array}{c}\text { Lesson preparation level } \\
\text { Q\&A level }\end{array}$ \\
\hline & & Highlight key points and difficulties \\
\hline & & Whether to use media such as multimedia \\
\hline & & Combination of multiple teaching methods \\
\hline & teaching method & Stimulate students' initiative \\
\hline & & Improve students' creative thinking \\
\hline & & Active classroom atmosphere \\
\hline & & Strong teacher-student interaction ability \\
\hline & & Combination of theory and practice \\
\hline & & Clear teaching goals \\
\hline & Teaching content & Interdisciplinarity \\
\hline & & Cultivate the level of practice \\
\hline & & Meet the teaching plan \\
\hline & & School time is on time \\
\hline & Teaching attitude & Prepare lessons carefully \\
\hline & & Full of energy \\
\hline & & Active atmosphere \\
\hline & Teaching effect & Assignment submitted on time \\
\hline
\end{tabular}
courses of information technology integrated engineering

Table 1. The evaluation index system of teaching effect 
management, they are very applicable to almost all disciplines.

The evaluation results are divided into five grades by using the scoring standards commonly used in the course effect evaluation. The range of relative scores of each grade is shown in Table 2.

Table 2. Correspondence of grade standard

\begin{tabular}{cc}
\hline Score range/min & Evaluation grade \\
\hline$<6$ & failed \\
$6-7$ & qualified \\
$7.1-8$ & medium \\
$8.1-9$ & good \\
$9.1-10$ & excellent
\end{tabular}

The evaluation index system of professional courses teaching effect of information technology integrated engineering management has the following characteristics: 1 . The structure is simple and clear, and the evaluator is easy to understand and value judge. 2 . All factors affecting the evaluation of teaching effect are considered, including course design, class preparation, teaching process and so on. The design of the index system considers the course characteristics of information technology integrated engineering management as a whole, including every link involved in teaching activities. 3. The same standard is adopted to investigate the classroom teaching quality of all teachers, so that college leaders can guide and grasp the realization state of teachers' classroom teaching objectives from a macro perspective. The implementation process is simple and the results are relatively reliable.

\subsection{Evaluation of professional course teaching effect of information technology integrated engineering management based on PSO-K-means}

The evaluation of professional course teaching effect of information technology integrated engineering management based on PSO-K-means runs K-means clustering algorithm in each iteration of particle swarm optimization, and the clustering results are used as the particle fitness of the evaluation process.

\section{Improved sample division decision function}

When the sample has label data, the method of dividing the sample into the cluster closest to the Euclidean distance of the centroid can not make good use of domain knowledge. It is necessary to comprehensively consider the centroid distance, the category and quantity of existing label data in the cluster [19]. For any sample data $X_{i}$ and a sample set $C_{j}$, it can define the function:

$$
\begin{aligned}
& \operatorname{semi}\left(X_{i}, C_{j}\right)=\text { cannot_linked }\left(X_{i}, C_{j}\right) \\
& +\operatorname{different}\left(X_{i}, C_{j}\right)-\left(\text { must_linked }\left(X_{i}, C_{j}\right)+\operatorname{same}\left(X_{i}, C_{j}\right)\right)
\end{aligned}
$$

Where: cannot_linked $\left(X_{i}, C_{j}\right)$ represents the number of samples in the set $C_{j}$ with cannot_linked relationship with $X_{i} ;$ different $\left(X_{i}, C_{j}\right)$ represents the number of samples with different category labels from $X_{i}$ in set $C_{j} ;$ must_linked $\left(X_{i}, C_{j}\right)$ represents the number of samples in the set $C_{j}$ that have must_linked relationship with $X_{i} ; \operatorname{same}\left(X_{i}, C_{j}\right)$ represents the number of samples in set $C_{j}$ with the same category label as $X_{i}$. In addition, if $X_{i}$ is unlabeled data, the value of the semi function is 0 .

Formula (7) is the statistics of the number of label data in a cluster. When considering whether to divide a data $X_{i}$ into cluster $C_{j}$, in addition to the Euclidean distance, it also depends on whether the existing label data in cluster $C_{j}$ and $X_{i}$ are the same label. If the same $\left(X_{i}, C_{j}\right)$ value is large, it indicates that different labels in cluster $C_{j}$ are proofread, and $X_{i}$ is not inclined to be divided into $C_{j}$, otherwise it is the opposite.

The improved algorithm classifies the sample $X_{i}$ into the cluster $C_{k}(k=1,2, \cdots, K)$ that minimizes the value of formula (8) according to the function of formula (7).

$$
J=\sum_{j=1}^{m}\left(X_{i j}-C_{k j}\right)^{2}+\lambda \times \operatorname{semi}\left(X_{i}, C_{k}\right)
$$

The value of $\lambda$ is calculated according to formula (9):

$$
\lambda=\frac{\sum_{k=1}^{K} \sum_{j=1}^{m}\left(X_{i j}-C_{k j}\right)^{2}}{N_{\text {semi }}}
$$

In the above formula, $N_{\text {semi }}$ is the number of samples of all supervision information; $\sum_{k=1}^{K} \sum_{j=1}^{m}\left(X_{i j}-C_{k j}\right)^{2}$ is the sum of Euclidean distances from sample $X_{i}$ to all centroids.

Compared with the traditional Euclidean distance determination method, the new determination function 
adds semi supervised information $\lambda \times \operatorname{semi}\left(X_{i}, C_{k}\right)$, balances the conflict between distance and category, and realizes the correct division of samples.

\section{Definition of objective function}

The linear combination of cluster dispersion and cluster impurity is used as the objective function of evaluation and optimization of course teaching effect:

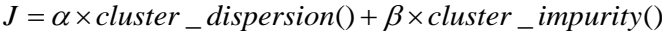

In formula (10): cluster_dispersion() is the distance measure of unsupervised learning. Generally, the sum of the distances of the due centroids of all samples is used as the dispersion measure; cluster_impurity() is a measure of label data purity in supervised learning clusters, that is, to measure whether the label data labels in the same cluster are as consistent as possible. Gini index is generally used as the impure measure. The above two metrics are substituted into equation (10) respectively, and the optimized objective function is:

$$
J=\left(\alpha \times \sum_{k=1}^{K} \sum_{i_{k}}^{n_{k}} \sum_{j=1}^{m}\left(X_{i j}-C_{k j}\right)^{2}+\lambda_{k} \times \operatorname{semi}_{k}()+\beta \times \operatorname{Gini}()\right)
$$

Where: $\sum_{k=1}^{K} \sum_{i_{k}}^{n_{k}} \sum_{j=1}^{m}\left(X_{i k j}-C_{k j}\right)^{2}$

distances from all samples to their centroid; $\lambda_{k}$ is the average Euclidean distance from the sample to the centroid in the $k_{\text {-th }}$ cluster; $s e m i_{k}$ is the number of supervisory information of the $k$-th cluster.

\section{Particle design}

In order to give full play to the advantages of particle swarm optimization algorithm and make the matching between search space and clustering space more natural, each particle represents a group of $K$ centroids, the corresponding data structure is a vector containing $K$ elements, and each element represents a point in Euclidean space. By moving to the global optimum, the centroid of clustering is also optimized.

\section{Particle fitness function}

The particle fitness is defined as fit ()$=-$ fun (). If each particle is clustered separately, it is natural to use the evaluation index of the clustering result as the particle fitness. The smaller the fun () value is, the larger the fit () value is, and the better the clustering result is; Accordingly, the higher the particle fitness is.

\section{Flow of PSO-K-means algorithm}

Input: data set $D$, maximum number of iterations $N$, number of clusters $K$, initial particle number $P_{n}$, maximum particle number $P_{\max }$, particle dynamic management sensitivity index $S$.

Output: dataset with class label $D$ and clustering accuracy.

(1) Initialize particle swarm

$K$ cluster initial centroids are randomly generated, and the array composed of $K$ points is initialized to the initial position of a particle, which is repeated [20], forming the initial position and initial velocity of $P_{n}$ particles.

(2) K-means clustering

For a group of centroids represented by each particle, it can divide each sample into the nearest cluster, and then calculate the fit () of each particle.

(3) Update the individual optimal $P_{i}$ and global optimal $P_{g}$ according to the particle fitness

(4) Particle movement.

Update particle velocity and particle position.

(5) Dynamically managed population

(a) When the global optimum of particle swarm does not change for $s$ times, the positions of two particles whose individual optimum is frequently updated are combined into the initial position, and the average velocity of all particles is taken as the initial velocity.

(b) Particle swarm optimization changes the global optimization $s$ times continuously, and dynamically deletes the particles with the least-frequent individual optimization updates.

(c) If the upper limit of particle population is reached and the optimal continuous $S$ times does not change, a particle is dynamically added to replace the non global optimal particle with the least frequently updated individual optimal particle, and the positions of the two frequently updated individual optimal particles are combined into the initial position, with the average velocity of all particles as the initial velocity.

(6) Judge whether the maximum number of iterations $N$ is reached. If so, the clustering accuracy is output. Otherwise, return to step (2) to continue the iteration.

PSO-K-means algorithm makes the search space of particle swarm optimization algorithm correspond to the clustering space more naturally, and uses the position of each particle to represent the initial centroid position. Because the particle velocity changes according to the current position, the particle velocity is faster when it is far away from the higher quality center. When approaching the center of mass, the speed slows down and can continuously move towards the best quality center $f$ , so the better quality center can be found quickly. The Euclidean distance and supervision information are combined to determine the clusters to be divided, and the conflict between Euclidean distance and label attributes is well balanced. Therefore, the algorithm has better clustering accuracy and can obtain more accurate evaluation results of professional courses teaching effect 
of information technology integrated engineering management.

\section{Experimental analysis}

The research method is applied to the teaching effect evaluation of engineering management courses in a university. In order to realize the good integration of information technology and engineering management courses in the teaching of engineering management courses in the University, the information technology course scores and class hours are set in the engineering management specialty of the University, as shown in Table 3.

From the experimental results in Table 3, it can be seen that the engineering management specialty of the university has set up many information technology related courses such as computer foundation, $\mathrm{C}$ language programming, computer comprehensive course design, intelligent civil engineering, management principles and engineering project management, so as to realize the good integration of information technology and engineering management courses.

Table 3. Information Technology Courses for Engineering Management Majors

\begin{tabular}{ccccc}
\hline category & Course Title & credit & In-class hours & Computer hours \\
\hline \multirow{2}{*}{ Basic Information Technology Course } & Computer Basics & 2 & 30 & 10 \\
& C language programming & 3 & 30 & 20 \\
& Computer Comprehensive Course Design & 1 & 14 \\
Engineering project management & Smart Civil Engineering & 1 & 34 \\
Project cost management & Principles of Management & 2 & 50 \\
Engineering contract management & Project Management Information System & 3 & 50 \\
& Engineering contract management & 3 & 34 \\
& Engineering economics & 3 & 50
\end{tabular}

Table 4. Weight calculation results of the evaluation index system

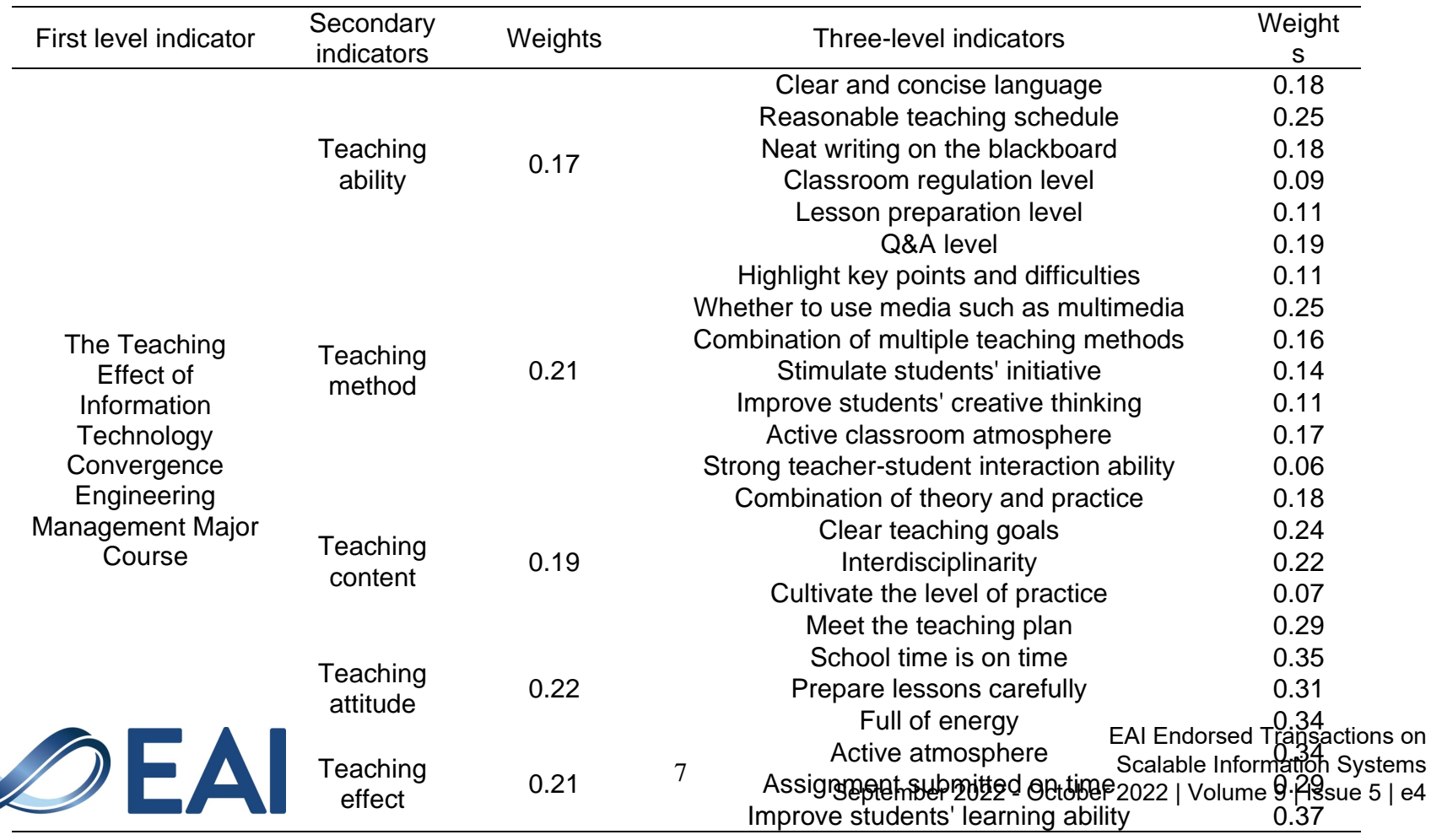


In order to verify the effectiveness of this method, 20 iterative particles are selected in the experiment. The 20 particles in the experiment are divided into 5 groups and divided into 5 important indicators to improve the effectiveness of teaching evaluation. In order to ensure the effectiveness of the experimental data, the number of experimental iterations designed in the experiment is 100 . After 100 iterations, the effectiveness of the evaluation method is verified .

Using the method in this paper, the weight results of the teaching effect evaluation index system of information technology integrated engineering management in the university are obtained, as shown in Table 4.

The method in this paper is used to evaluate the teaching effect of the information technology courses integrated into the engineering management specialty of the University. The evaluation results are qualified and above courses. The statistical results are shown in Figure 1 .

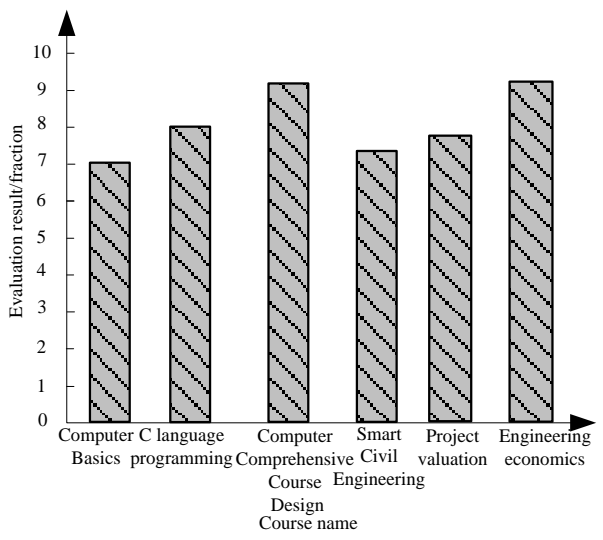

Figure 1. Teaching effect evaluation results of courses of passing grade and above

According to the evaluation results of the teaching effect of the course in Figure 1, the six courses teaching effects of the information technology integrated engineering management of computer foundation, $\mathrm{C}$ language, computer comprehensive course design, intelligent civil engineering, engineering valuation and engineering economics are all qualified or above, indicating that the students majoring in engineering management are highly satisfied with the teaching effect of the above courses. Among them, the highest satisfaction can reach more than 9 points. This is because this method constructs an index system in line with the actual situation and calculates the weight of each index, which improves the effectiveness of this method.

The method in this paper is used to evaluate the teaching effect of the information technology courses integrated into the engineering management of the University. The evaluation results are unqualified courses, and the statistical results are shown in Figure 2.

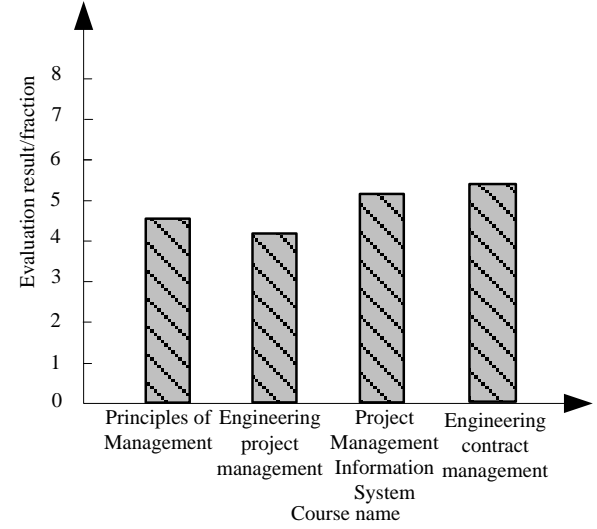

Figure 2. Evaluation results of the teaching effect of failed courses

According to the evaluation results of the teaching effect of the course in Figure 2, the teaching effect of the four information technology integrated engineering management courses of management principle, engineering project management, engineering management information system and engineering contract management is below the pass level, indicating that the engineering management students are less satisfied with the teaching effect of the above courses. We should fully analyze the reasons for the low teaching effect scores of the above information technology integrated engineering management courses, so as to improve the overall teaching effect of the information technology integrated engineering management courses.

In order to clarify the reasons for the low scores of the four information technology integrated engineering management courses of management principle, engineering project management, engineering management information system and engineering contract management, the scoring results of the secondary indicators of the above four courses are counted, and the statistical results are shown in Figure 3.

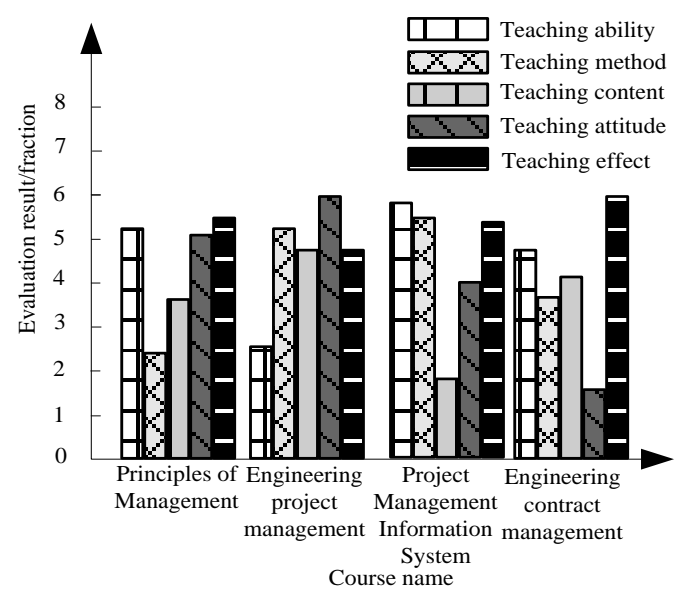

Figure 3. Evaluation results of the secondary indicators of failed courses

By analyzing the experimental results in Figure 3, the main reason for the low score of the teaching effect of the principle of management course is the teaching 
methods. The teachers of the principle of management course should adjust the teaching methods and select the teaching methods more suitable for students and course acceptance; The main reason for the low score of teaching effect of engineering project management course is teaching ability. Teachers of engineering project management course should summarize their deficiencies in teaching ability and improve their teaching ability; The main reason for the low teaching effect score of engineering management information system course is the teaching content. The teaching teachers of engineering management information system course should enrich the teaching content, improve the scientificity and rationality of the teaching content, and ensure the good teaching effect of the course from the improvement of the teaching content. It can be seen that the evaluation effect of this method is high, and it can fully and accurately analyze the effectiveness of each course.

Taking the principles of management course and engineering project management course as examples, the evaluation results of various indicators in the teaching methods for principles of management course and the evaluation results of various indicators in the teaching ability of engineering project management course are counted respectively. The statistical results are shown in Figure 4.

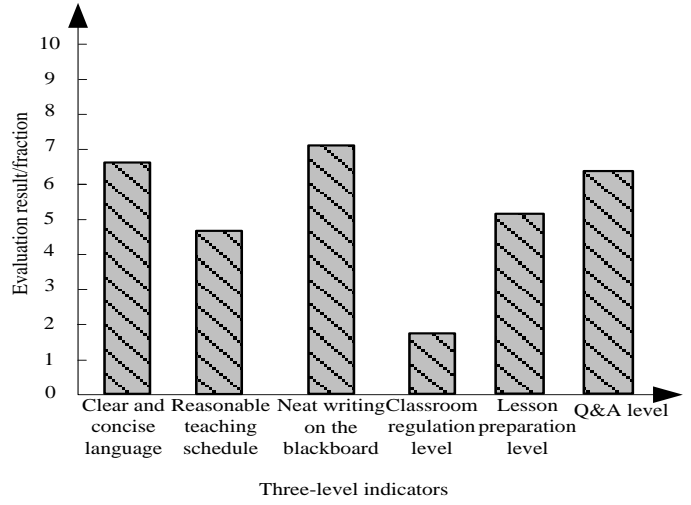

(a)Teaching method

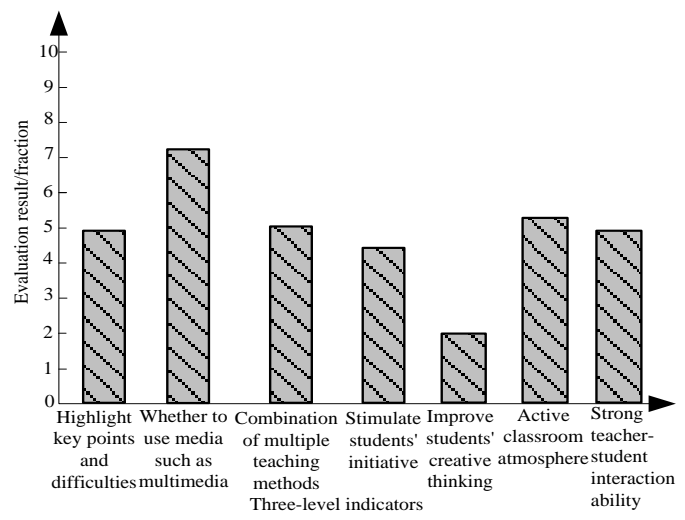

(b) Teaching ability

Figure 4. Evaluation results of three-level indicators

As can be seen from the experimental results in Figure 4, the main reason for the low score of teaching methods in the principle of management course is the poor level of classroom regulation. During the teaching process, teachers of the principle of management course should pay attention to the level of classroom regulation, maintain an active classroom atmosphere and enhance students' interest in the course. The main reason for the low score of teaching methods in engineering project management course is the poor level of improving students' creative thinking. In the teaching process of engineering project management course, teachers should fully combine the relationship between information technology and engineering project management and improve students' creative thinking through practical engineering project management examples.

It can be seen from the above experimental results that the method in this paper can not only evaluate the teaching effect of information technology integrated engineering management course, but also clarify the reasons for the low teaching effect according to the evaluation results, which has high practicability.

\section{Discussion}

This paper studies the evaluation method for professional course teaching effect of information technology integrated engineering management based on data clustering, and uses K-means clustering algorithm to obtain the teaching effect evaluation results of information technology integrated engineering management. Data mining is the process of automatically discovering useful information in large data repositories. It is an indispensable part of knowledge discovery in the field of data processing. At present, the research of data mining in colleges and universities in China has been carried out, and its application in education is in the development stage. The data clustering method in data mining is applied to the evaluation of teaching effect of information technology integrated engineering management. The evaluation of professional course teaching effect of information technology integrated engineering management appears with classroom teaching, and its functions are as follows:

(1) Diagnostic function: is to evaluate the classroom teaching effect of the professional course of information technology integrated engineering management, and judge the quality, level, effectiveness and defects of all aspects of the teaching of the information technology integrated engineering management course. Comprehensive and objective evaluation can explain the reasons for students' poor performance to a great extent and find out the main reasons. The evaluation of classroom teaching effect is equivalent to a rigorous scientific diagnosis of teaching.

(2) Incentive effect: through the evaluation of course teaching effect, it can reflect the teaching effect of teachers and students' learning achievements, supervise and strengthen teachers and students, and effectively promote classroom learning.

(3) Adjustment function: through the evaluation of course teaching effect, teachers and students can clarify 
their teaching and learning situation, so that they can revise the teaching plan and adjust the teaching behavior according to the feedback information, so as to achieve the specified objectives.

(4) Teaching function: teaching evaluation itself is also a kind of teaching activity. Through this activity, it can promote the development of students' knowledge, skills, intelligence and morality.

The evaluation of professional course teaching effect of information technology integrated engineering management can promote teachers to grow better and faster. In classroom teaching evaluation, we can fully understand the overall teaching level of teachers teaching in the classroom, find the advantages and existing problems of teachers in the teaching process, and understand their advantages and disadvantages in classroom teaching practice through teachers, so as to carry forward their advantages, solve and correct their deficiencies, and improve their own teaching level, purposefully implement teaching to improve the effectiveness of classroom teaching. Through classroom teaching evaluation, evaluators and teachers can better understand the overall performance and basic situation of students, such as scientific thinking, basic skills, learning attitude, knowledge base and so on. In this way, we can conduct in-depth discussion and research from the actual situation of students and find a teaching model suitable for students, so as to improve the proportion of effective activities in classroom teaching and can better improve and develop classroom teaching reform. We can use classroom teaching evaluation to view the shortcomings and advantages of classroom teaching from multiple angles, and timely study and analyze the unreasonable part to find a solution, so that the teaching reform experiment can be developed and improved in the process of continuous testing, so as to play a better role in teaching.

\section{Conclusion}

With the rapid development of social economy, information technology is more and more widely used in economic life. The integration of information technology and engineering management courses is a profound change in management mode in the field of engineering management. Although there are a series of problems in China's information management at this stage, as long as we continue to explore and dare to innovate, the integration of China's engineering management specialty and information technology will achieve great success. This paper studies the evaluation method for professional course teaching effect of information technology integrated engineering management based on data clustering, so as to provide a basis for the teaching reform of engineering management specialty. This method can provide a more scientific basis for teacher management of engineering management specialty and provide detailed feedback information for schools to improve the teaching level of engineering management specialty. Data clustering method is an important method often used in evaluation methods. Data clustering method can clearly reflect the differences of teachers' teaching quality and provide meaningful information for course teaching quality management. This method is used to deeply explore the courses teaching quality of information technology integrated engineering management in classroom in colleges and universities, form a new comprehensive evaluation index system, provide more information and scientific basis for education administrative departments to understand and evaluate teachers' teaching performance, promote colleges and universities to strengthen teaching management, improve teaching quality, and fully mobilize teachers' teaching and students' learning enthusiasm.

\section{Acknowledgements.}

This paper is funded by the 14th Five-Year Plan of Chongqing Education Science with No.2021-GX-039

\section{References}

[1] Al-Abbas, M. , Fawaz, W. , Ghajar, R. , Rjeily, C. A. \& Saab, S. S. (2020). Toward an improvement of engineering teaming skills through an in-house professionalism course. IEEE Transactions on Education;35(03): 1-10.

[2] Wustmans, M. , Haubold, T. \& Bruens, B. (2021). Bridging trends and patents: combining different data sources for the evaluation of innovation fields in blockchain technology. IEEE Transactions on Engineering Management;15(12): 113.

[3] Elia, G., Margherita, A. \& Passiante, G. (2020). Management engineering: a new perspective on the integration of engineering and management knowledge. IEEE Transactions on Engineering Management; 21(17): $1-13$.

[4] Carayannis, E. , Giudice, M. D. , Tarba, S. \& Soto-Acosta, P. (2021). Editorial: building entrepreneurial ecosystems: exploring ambidexterity in technology and engineering management. IEEE Transactions on Engineering Management; 68(2): 347-349.

[5] Luo,Y. L. , Deng, K. Y. , Tian, G. \& Luo, Y. L. (2020). Immersion VR Teaching System "VisAll". Computer Simulation; 37(11): 200-204+309.

[6] Damaj, I. , El-Abd, M. , Kranov, A. A. \& Deboer, J. (2020). Guest editorial special issue on project-based, senior design, and capstone courses in engineering education. IEEE Transactions on Education; 63(2): 79-81.

[7] Sunba, K. \& Rogers, K. (2020). The effect of teaching methodology and course duration on student performance at different assessment types across different cognitive levels as defined by bloom's taxonomy. The FASEB Journal; 34(01): 1-5.

[8] Sheng, W. , Wang, X. , Wang, Z. , Li, Q. \& Chen, S. (2020). A differential evolution algorithm with adaptive niching and $\mathrm{k}$-means operation for data clustering. IEEE Transactions on Cybernetics; 34(21): 1-15.

[9] Song, Y. , Lu, J. , Lu, H. \& Zhang, G. (2020). Fuzzy clustering-based adaptive regression for drifting data streams. IEEE Transactions on Fuzzy Systems; 28(3): 544557. 
[10] Fang, F. , Qiu, L. \& Yuan, S. (2020). Adaptive core fusionbased density peak clustering for complex data with arbitrary shapes and densities. Pattern Recognition; 107(3): 107452.

[11] Geng D Z , Xu Q (2021). High-Dimensional Mixed Attribute Data Mining Method Based on K-Means Clustering Algorithm. Computer Simulation; 38(2) : 308312.

[12] Shuai L, Shuai W, Xinyu L, et al, Human Inertial Thinking Strategy: A Novel Fuzzy Reasoning Mechanism for IoTAssisted Visual Monitoring, . IEEE Internet of Things Journal, online first, 2022, 10.1109/JIOT.2022.3142115

[13] Gandhi, G. S. , Vikas, K. , Ratnam, V. \& Babu, K. S. (2020). Grid clustering and fuzzy reinforcement-learning based energy-efficient data aggregation scheme for distributed wsn. IET Communications; 14(16): 2840-2848.

[14] Liu S, Wang S, Liu X, et al. Fuzzy Detection aided Realtime and Robust Visual Tracking under Complex Environments. IEEE Transactions on Fuzzy Systems, 2021, 29(1), 90-102

[15] Wang, Y., Wang, Y. X. \& Singh, A. (2019). A theoretical analysis of noisy sparse subspace clustering on dimensionality-reduced data. IEEE Transactions on Information Theory; 65(2): 685-706.

[16] Shuai L, Dongye L, Khan M, et al. Effective Template Update Mechanism in Visual Tracking with Background Clutter. Neurocomputing, 2021, 458, 615-625.

[17] Kulakowski, K. \& Lipovetsky, S. (2021). Understanding the analytic hierarchy process. Technometrics; 63(2): 278279.

[18] Liu S, Wang S, Liu X, et al, Human Memory Update Strategy: A Multi-Layer Template Update Mechanism for Remote Visual Monitoring, IEEE Transactions on Multimedia, 2021, 23, 2188-2198

[19] Elia, G. , Margherita, A. \& Passiante, G. (2020). Management engineering: a new perspective on the integration of engineering and management knowledge. IEEE Transactions on Engineering Management; 12(4): 113.

[20] Quesada, J. , Calvo, I. , Sancho, J., Sebastian, R. \& Castro, M. (2020). A design-oriented engineering course involving interactions with stakeholders. IEEE Transactions on Education; 15(9): 1-8. 